\title{
Editorial
}

\section{Geothermal Energy: Delivering on the Global Potential}

\section{Paul L. Younger}

School of Engineering, University of Glasgow, Glasgow G23 5EB, Scotland, UK; E-Mail: paul.younger@glasgow.ac.uk; Tel.: +44-141-330-5042

Academic Editor: Enrico Sciubba

Received: 8 October 2015 / Accepted: 9 October 2015 / Published: 19 October 2015

\begin{abstract}
Geothermal energy has been harnessed for recreational uses for millennia, but only for electricity generation for a little over a century. Although geothermal is unique amongst renewables for its baseload and renewable heat provision capabilities, uptake continues to lag far behind that of solar and wind. This is mainly attributable to (i) uncertainties over resource availability in poorly-explored reservoirs and (ii) the concentration of full-lifetime costs into early-stage capital expenditure (capex). Recent advances in reservoir characterization techniques are beginning to narrow the bounds of exploration uncertainty, both by improving estimates of reservoir geometry and properties, and by providing pre-drilling estimates of temperature at depth. Advances in drilling technologies and management have potential to significantly lower initial capex, while operating expenditure is being further reduced by more effective reservoir management-supported by robust models - and increasingly efficient energy conversion systems (flash, binary and combined-heat-and-power). Advances in characterization and modelling are also improving management of shallow low-enthalpy resources that can only be exploited using heat-pump technology. Taken together with increased public appreciation of the benefits of geothermal, the technology is finally ready to take its place as a mainstream renewable technology, exploited far beyond its traditional confines in the world's volcanic regions.
\end{abstract}

Keywords: binary cycle; drilling; energy; exploration; geophysics; geothermal; heat; heat-pump; power plant; renewable 


\section{Introduction}

Geothermal energy is thermal energy produced naturally in the planetary interior [1,2], principally by the decay of radioisotopes of potassium, uranium and thorium [3]. As such, it is the only renewable energy source independent of solar radiation and/or the gravitational attraction of the sun and moon [4]. Since time immemorial, geothermal energy emerging at the earth's surface as natural hot springs has been instinctively harnessed by human beings - and indeed other animals, most famously the macaque (snow monkeys) of Japan [5] — as a source of comfort and cleansing. For instance, in the ancient Roman Empire, few natural hot springs were overlooked for their potential to service the hot water demands of the public baths that were such an indispensable part of army life and wider Roman culture [2]. Natural thermal springs have also long been used for laundry purposes, and even for cooking. All of these uses - together with space heating and various industrial heating applications - are instances of direct use of geothermal resources [6].

The only other, indirect, use of geothermal energy is for power generation. Where high-enthalpy reservoirs exist, this is most commonly achieved using various types of flash plant, in which the pressure of hot, deep fluids is carefully manipulated to achieve quantitative conversion of hot water to high-pressure steam, which can then be used to spin conventional steam turbines [7]. The earliest plant of this type was commissioned little over a century ago at Larderello, Italy [2,7]. In cases where the temperature of the geothermal fluid is too low for flashing to steam, electricity can still be produced by means of "binary" power plants [4], in which a secondary working fluid with a far lower boiling point than water is heated via a heat-exchanger such that it is converted to a high-pressure gaseous phase, which again can spin a turbine.

As the water exiting a flash or binary geothermal power plant is typically still hot enough for myriad direct uses, geothermal energy is especially suited to combined-heat-and-power (CHP) applications [8]. If thus exploited, the overall efficiency of geothermal power conversion is far higher than for most other forms of energy. Furthermore, geothermal power plants are characterized by extremely high capacity factors (typically in excess of $90 \%$, with many over 95\%), which means that they are typically operated 24/7, producing copious amounts of baseload power and heat [6]. As geothermal power plants typically have very low carbon emissions, their ability to supply baseload puts them on a par with nuclear energy for overall performance [4,9], with none of the operational safety and hazardous waste management issues posed by nuclear.

The baseload power and heat production attributes of geothermal distinguish it from most other renewables [4]: although biomass CHP plants can perform similar service, they typically have far higher operating expenditure (opex) requirements than geothermal plants, due to the need to continually supply fuels of rather low energy-density; furthermore, their capacity factors tend to be rather lower than for geothermal, due to their greater maintenance requirements and vulnerability to interruptions of fuel supply. Solar, wind and wave notoriously suffer from intermittency, reflected in low capacity factors $(<30 \%)$; and although tidal power is highly predictable, any one plant still tends to have a capacity factor less than $60 \%$. The capacity factors for hydropower plants are seldom much greater. It is also important to note that wind, wave, tidal and hydropower cannot directly produce heat, and using the electricity they produce for conventional heating (i.e., without heat-pumps) is a very wasteful use of high-grade energy. 
While solar thermal energy is growing in importance, it is generally restricted to producing hot water and rarely manages to provide much space heating.

However, despite all these advantages, the uptake of geothermal energy has to date been disappointing, with annual growth rates in installed capacity since 2004 averaging around 5\%, which compares highly unfavourably with the equivalent rates for wind and solar PV (25\%-30\%) [10]. While lack of appropriate technology for deep, mid-enthalpy systems is partly to blame, and is exacerbated by a persistent lack of public understanding of invisible, subsurface phenomena [11], discussions with investors and engineers throughout the geothermal sector invariably identify two common factors inhibiting more rapid uptake of geothermal energy across all enthalpy categories:

(i) uncertainties over resource availability in poorly-explored reservoirs; and

(ii) the cost profile, in which a large proportion of the full-lifetime costs of systems are concentrated in early-stage capital expenditure (capex).

Some of the solutions to these problems surely lie, at least in part, in the domain of economic policy instruments, such as dry-hole insurance schemes [12] and long-term loan arrangements. However, there is still ample scope for technological innovation to contribute to addressing the barriers to uptake [13], particularly in non-volcanic regions where the majority of resources are low- to mid-enthalpy ("petrothermal") resources in deep strata of unexceptional natural permeability [10].

This paper critically appraises some recently-reported innovations and identifies gaps for future developments, taking a broad view across the entire spectrum of geothermal technology: from drilling and reservoir stimulation, through reservoir modelling and management, to design and operation of mechanical plant at surface that completes the energy conversion process. It also ranges across the entire range of enthalpies found in the subsurface [14], and concludes with a proposal for a whole-system research agenda to expedite realization of the full global potential of geothermal energy.

\section{Historical Context and Resource Categorization}

The development of modern geothermal energy technology has had at least two dimensions: from high-enthalpy to low-enthalpy resources; and from direct use, through indirect use to CHP and heat-pump applications $[2,6,9,10,15]$. The earliest impetus for technological development was as an alternative to imported fossil fuels in countries that lacked these in abundance. While the prime motivations related to economics and securing energy supplies, the air-quality benefits of switching from smog-producing coal and oil combustion to the near-zero particulate emissions of geothermal was soon recognized as an important auxiliary advantage [16]. By the dawn of the 21 st Century, the principal motivation for developing geothermal had become its low-carbon and renewable credentials. In the case of geothermal, these credentials are not as straightforward to assure as for solar and wind. For instance, the renewability of geothermal can be compromised by poor reservoir management - especially any shortcomings in the reinjection of cooled geothermal fluids - which can lead to quite marked overdraft of the resource base, at least locally and temporarily (albeit the time-scale may be decadal). Similarly, some geothermal systems can have quite high $\mathrm{CO}_{2}$ emissions, especially in volcanic regions where the magma conduits cut through carbonate sedimentary rocks (as in much of Italy, for instance; [17]). However, the majority of geothermal systems have very low carbon emissions, with systems used only 
for heating purposes having some of the lowest carbon emissions of any renewable technologies, at around $4 \mathrm{~g}$ of $\mathrm{CO}_{2}$ equivalent per $\mathrm{kWh}[9,18]$.

As previously noted, the very earliest human use of geothermal resources was for recreational direct-use purposes [2] with electricity generation commencing only in 1912 at Larderello (Italy) [7]. These two historic uses exploit, respectively, low and high enthalpy resources. Far more recent are the various attempts to exploit very low enthalpy systems (which is solely for direct-use purposes and requires the use of heat-pumps) and mid-enthalpy systems (mainly for direct use, but also potentially for power generation — and thus CHP — by means of binary cycle power plants; [6-9,19]). Meanwhile, deep drilling in Iceland has successfully intercepted a super-critical geothermal reservoir [20], which had originally been discovered by accident. If super-critical reservoirs can be successfully engineered - without inducing pressure decreases within the reservoirs that would take them below the critical point - the rewards will be high indeed: a single super-critical geothermal well can be expected to produce an order of magnitude more energy than a well of similar dimensions accessing only sub-critical high-enthalpy resources [20].

Given these recent developments at both ends of the enthalpy spectrum, the old bipartite categorization of geothermal resources into low- and high-enthalpy systems [1,9] is no longer fit for purpose [14]. A more refined categorization of resources, which corresponds quite closely with the optimal domains for application of different energy conversion technologies, was recently proposed by Younger [14], and is further developed here in graphical form (Figure 1).

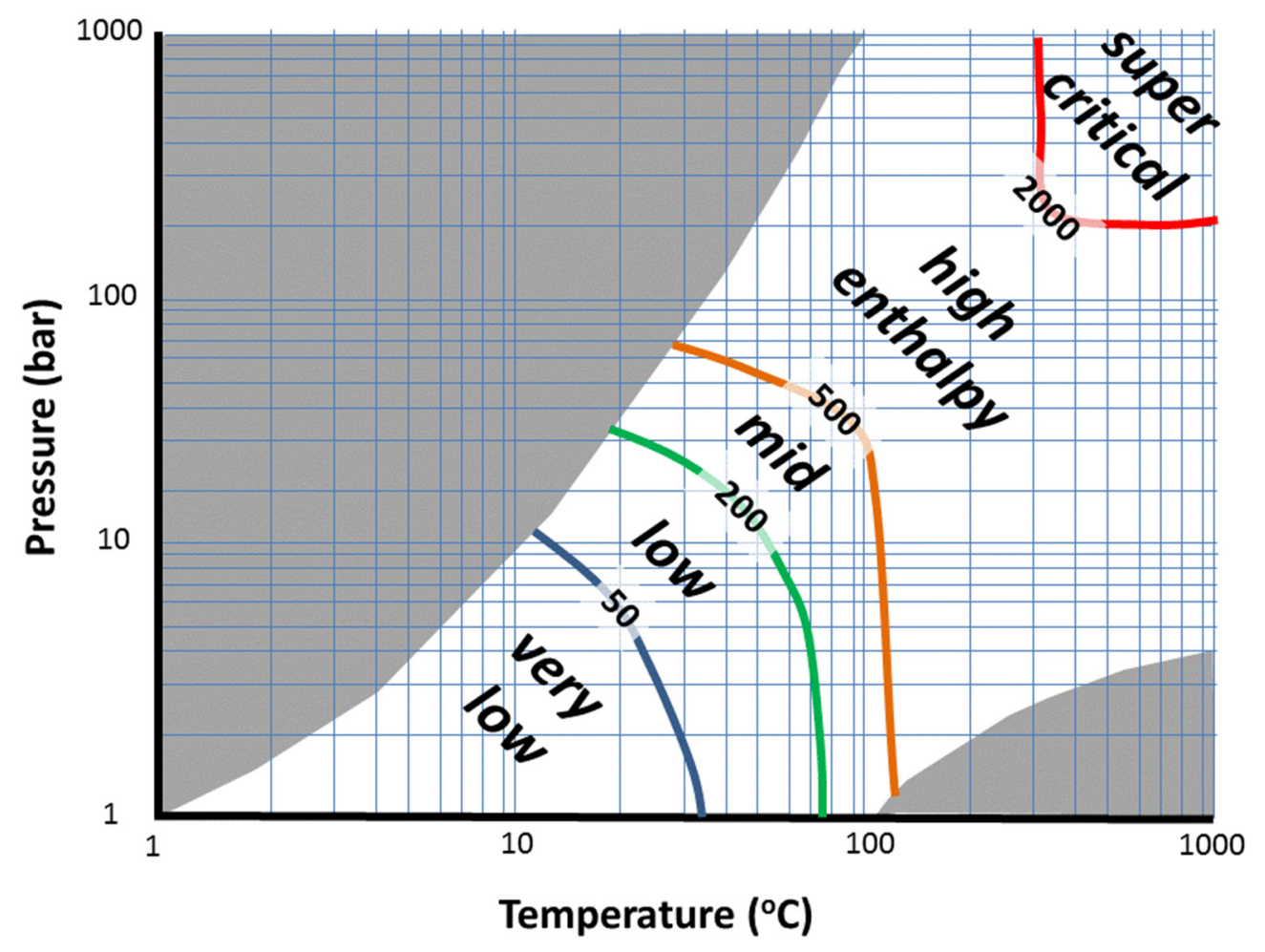

Figure 1. Categorization of geothermal resources on the basis of enthalpy. The shaded areas indicate parts of the parameter space that are rare/impossible in natural systems. The numbers on the lines dividing the different enthalpy categories are approximate values of enthalpy in $\mathrm{kJ} / \mathrm{kg}$. 


\section{Recent Innovations}

\subsection{Spheres of Endeavour}

It is both the fascination and the challenge of geothermal energy that it is a multifaceted business, requiring critical inputs from a wide range of engineering, natural science and social science disciplines. As in all commercial spheres, not all significant innovations are reported in the open literature, either due to economic sensitivities, or simply due to a lack of a pressure for industrial innovators to publish. This paper is also focused on introducing and explaining the context for this geothermal Special Issue of the journal Energies. Hence, the account that follows will inevitably be partial. In broad terms, however, it is clear that significant innovations in geothermal energy have been made in the following areas:

- Reservoir exploration and development;

- Reservoir management and modelling;

- Design, operation and maintenance of energy conversion technologies; and

- Socio-economic constraints on geothermal energy use.

Each of these areas is explored in the following sub-sections.

\subsection{Reservoir Exploration and Development}

The concept of "reservoir" is seldom discussed in connection with very low-enthalpy geothermal resources exploited using closed- or open-loop heat-pump systems. There has been a tendency to tacitly assume that individual heat-pump systems are unlikely to interfere with each other, so that the overall heat (and water) balance of the "reservoir" can be neglected. Where ground-coupled heat-pump systems (GCHPS) are used for individual dwellings in rural areas, this tacit assumption may be unproblematic. However, for larger GCHPS, and wherever neighbouring systems occur in close proximity to one another, failure to characterise and manage the ground exploited by the system can lead to poor performance, manifest in coefficients of performance (COPs) well below the usual minimal target design value of 3 [15]. It can also result in mutual interference between adjoining subsurface heat-exchangers, diminishing the ability of a given volume of ground to support the desired heating/cooling load [21]. A volume of ground used for such purposes has been termed an "aestifer" [22], being a body of geological material that stores and transmits heat. As such, an aestifer is analogous to the more familiar "aquifer" that stores and transmits water. Indeed, for large open-loop systems an aestifer might be entirely identified with an aquifer. However, because heat conduction is not limited solely to permeable rocks, non-aquifer lithologies may fall within the boundaries of an aestifer, particularly where the GCHPS exploiting it is a large closed-loop system. In such cases, characterisation of an aestifer involves delineation of spatial boundaries and determination of its intrinsic thermal properties, especially thermal conductivity and specific heat capacity [22].

Clearly drilling, in situ testing, sample retrieval and laboratory testing all have crucial parts to play in identifying fields of thermal properties within an aestifer, and indeed of point-specific temperature as a key state variable. However, as in all other arenas of geological exploration, such direct measurement methods can never fully capture the totality of the parameter fields. It is in this connection that geophysical methods can play an important role, both in guiding the siting of the limited number of 
boreholes that the project can afford, and in interpolating petrophysical properties between boreholes. While routinely used in applied investigations of geology at substantial depths (e.g., for mineral prospecting, hydrocarbon exploration and high-enthalpy geothermal exploration), the overall neglect of aestifer characterization in very low-enthalpy GCHPS applications is reflected in a scarcity of geophysical investigations of shallow soils and rocks coupled to heat pumps. However, in a rigorous review of experiences to date, Hermans et al. [23] have found that a combination of electrical resistivity tomography (ERT), the self-potential method (SP) and distributed temperature sensing (DTS) can provide reliable sensing of variations in subsurface temperatures and, by joint inversion with other geoscientific information, powerful insights into spatial variations in thermal conductivity and specific heat capacity.

A particular category of aestifer with potentially widespread use in many old industrial conurbations in Europe and North America are flooded coalmines [24]. Large open-loop GCHPS exploiting these are operating successfully in Springhill (Nova Scotia), Heerlen (Netherlands) and Miéres (Spain) [14]. As the movement of both ground water and heat in flooded mine workings is typically complex, sometimes involving turbulent flow conditions atypical of most natural aquifers, assessment of these aestifers is particularly challenging. However, statutory compilation of mine plans in most jurisdictions means that records of former mines are generally quite good, at least for mines dating from the final quarter of the 19th Century onwards. This certainly assists in the characterization of thermal properties. Ironically, however, the amount of detail obtained from such plans can be overwhelming, and difficult to analyse over very large areas. Hence, simplified modelling approaches are often most appropriate for regional-scale evaluations of both the hydrogeology [25] and thermal behaviour [24] of flooded coal workings. For instance, prima facie reasoning, assuming typical values for several key thermal properties, suggests that a first approximation of the amount of thermal energy that can be extracted from abandoned coalmines can be estimated from historic coal production figures [24]. Using median parameter values, it is estimated that about $2.5 \mathrm{MW}$ th ought to be extractable using heat pumps for every $10 \mathrm{Mt}$ of coal formerly mined from the flooded workings. While no substitute for site-specific investigations, this simplified approach can at least allow rapid screening of districts where more detailed studies seem most likely to prove fruitful. As a minimum, this suggests that $3000 \mathrm{MW}_{\text {th }}$ could be sustainably produced from the former coalmines of the European Union, delivering a carbon emissions reduction equivalent to around 5 MtCO2-equiv per annum [24].

Mid-enthalpy geothermal reservoirs (Figure 1) have the advantage over very low-enthalpy systems that heat pumps are not required to attain temperatures high enough for most space heating and hot water supply purposes. While a handful of studies have considered closed-loop boreholes for the exploitation of such reservoirs (e.g., [26]), most mid-enthalpy systems are predicated on open-loop pumping and reinjection of ground water that obtains its heat from the surrounding rocks. For this to be feasible, two factors are indispensable: sufficient permeability and sufficient heat flow. Frustratingly, many of the rocks with the best heat flow properties have indifferent permeability (the so-called "hot dry rock" scenario), so that reservoir stimulation techniques are necessary in order to obtain sufficient yields - this is the approach termed "engineered (or enhanced) geothermal systems" (EGS), and it has been the subject of several concerted investigations in the USA and Europe since the 1970s (e.g., [1,6,9]). In the last decade there has been increased appreciation that sufficient natural permeability can be encountered where boreholes intercept natural geological structures oriented suitably in relation to the present-day 
natural stress field; this was the case at Eastgate (northern England), for instance, where a geothermal exploration borehole proved the highest permeability yet recorded in deep granite anywhere in the world [27].

Whereas permeability is amenable to some degree of manipulation, the same cannot be said of petro-thermal properties. While archival heat flow estimates may well be improved by application of updated models, which more accurately allow for the effects of high topographic relief and/or the residual effects of palaeoclimatic conditions [28], the fundamental parameters of radiothermal heat production, thermal conductivity and specific heat capacity are essentially objective. That is not to say, however, that the methods for determining these parameters are beyond improvement. For instance, topography, atmospheric conditions and spatial patterns of heterogeneity can all affect measured levels of gamma-ray emissions from radiothermal source rocks. Hence enhanced data collection and inversion methods for spectral gamma surveys will facilitate more precise estimation of heat production and flow rates, helping refine selection of drilling targets, such as potassium-rich granites and thick sequences of black shales [3]. Nevertheless, quantification of heat production rates at depth is insufficient to accurately predict the spatial distribution of the warmest waters in overlying sedimentary strata-quantification of climatic influences (past and present) and convective ground water flow patterns are at least as important [29].

These factors are also important in the case of high-enthalpy systems [29], though constraints on upper-bound temperatures are also dependent on the maximum depth of hydrothermal circulation, which corresponds to the horizon of transition from brittle to plastic deformation, as revealed by an abrupt cessation of earthquake foci [30]. In the vicinity of major Quaternary volcanoes in Japan, for instance, this horizon approximates to the inferred $380{ }^{\circ} \mathrm{C}$ isotherm, beneath which seismicity, fracturing and hydrothermal convection are all observed to cease in granitic crust [30]. Within the zone of hydrothermal circulation, seismic processes may provide valuable insights into reservoir functioning. For instance, variations in mineral assemblages correlated with hydrothermal alteration are such that there is a negative correlation between reservoir temperature and seismic velocity anomalies at temperatures less than $\sim 220^{\circ} \mathrm{C}$, whereas at higher temperatures the correlation is positive [31]. Hence interpretation of natural seismic data may provide direct estimates of reservoir temperatures, in addition to its more orthodox applications in delineating spatial boundaries and internal structures in reservoirs [31].

The overall process of evaluation of high-enthalpy resources at the exploration stage is multi-faceted, effectively triangulating the best estimate of reservoir enthalpies (and other reservoir characteristics) from a range of alternative approaches using largely independent data-sets. The case of Chile offers a compelling worked example of how such an approach can be used to estimate future energy productivity for individual fields, and thence for an entire country in which no geothermal power plant has yet been developed [32]. Already, consideration is being given to developments even further into the future, when geothermal developments might follow the historical precedent of hydrocarbons and progress to offshore exploitation of submarine hydrothermal circulation systems, such as those associated with the Marsili Seamount in the southern Tyrrhenian Sea (Italy) [33] or with sea-floor spreading ridges off the northwestern coast of the USA [34].

Nevertheless, continued success in high-enthalpy exploration will require renewal of paradigms on the part of many practitioners. Given that the majority of highly productive systems developed to date have been associated with conspicuous stratovolcanoes, it is unsurprising that the most common 
exploration model is predicated on the search for hydrothermal systems associated with such features. However, in many dissimilar settings heat flows are just as elevated, yet geothermal exploration has barely commenced. The non-volcanic tracts of the East African Rift system are a case in point. A more open-minded approach to exploration paradigms will be required if valuable resources are not to be overlooked [35].

One such example of a paradigm shift in exploration relates to supercritical geothermal resources, the deliberate search for which was prompted by experiences of unanticipated interception of reservoirs with supercritical properties in Italy and Iceland. The engineering challenges in accessing and harnessing such high temperature $\left(>400^{\circ} \mathrm{C}\right)$, high-pressure $(>22 \mathrm{MPa})$ reservoirs are considerable, but have recently been substantially addressed at Krafla volcano by the Iceland Deep Drilling Project [20]. Recent theoretical analysis has clarified the conditions that give rise to supercritical conditions, as well as illuminating the likely frequency of occurrence and extent of such reservoirs [36]. The findings are encouraging, suggesting that a supercritical root zone can be expected to occur above young magmatic intrusions that underlie many well-known high-enthalpy reservoirs. Further deliberate exploration for supercritical reservoirs is currently scheduled in Iceland, Japan and New Zealand [34], with potential to develop production wells ten times more prolific than typical high-enthalpy wells. If this potential can be realized widely and at scale, the contribution of geothermal energy to the generation mix will be greatly enhanced.

\subsection{Reservoir Management and Modelling}

It is ironic that the management of deep, high-enthalpy geothermal reservoirs is far more advanced and exhaustively documented than that of the shallow, low-enthalpy variably-saturated soil systems ("aestifers") exploited using heat-pumps. In part this is because the uptake of GCHPS was, until the last decade or so, sufficiently modest that interference between adjoining installations could be safely overlooked. This is particularly so where GCHPS installations only serve single dwellings, with individual system capacities seldom exceeding $20 \mathrm{~kW}$. However, as there is a proliferation of multi-MW installations serving large commercial premises, scope increases for mutual interference between systems, as well as for cumulative depletion of the ability of the aestifer to continue to provide the heating and/or cooling services demanded of it [21,37,38]. Detailed, site-specific investigations of such cases are increasingly being reported [37,39], often supported by numerical modelling [37,40]. Such studies are providing the basis for pro-active regulation of open-loop GCHPS developments [38], although closed-loop systems continue to evade regulatory control in most jurisdictions. This is not simply a matter of legislative loopholes: modelling of closed-loop systems is often more complicated than for open-loop because of the occurrence of multi-phase fluid flow above the water table, and because of the complex geometry of shallow, looped heat-exchangers buried in soil. Analytical solutions to the latter problem have been obtained and applied [41], though these necessarily involve rather sweeping assumptions to be made about soil properties.

The management of mid-enthalpy reservoirs has received little more attention than GCHPS aestifers, though experience with exploiting such systems for district heating and CHP applications is rapidly growing. France was the earliest entrant into the large-scale use of mid-enthalpy systems, with a cluster of systems that have now been exploiting the deep Chalk aquifer in the Paris Basin for more than forty years [9]. More recently, favourable government support programs have led to around 200 projects 
coming forward in Germany [42], with annual production of geothermal heat and power increasing from

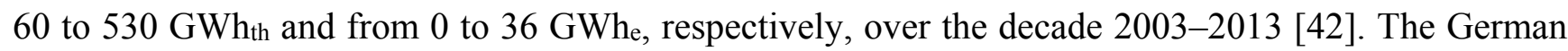
experience indicates that, even with a very supportive governance framework, most mid-enthalpy geothermal systems require around six years to proceed from initial concept to full commissioning [42].

As the most recent volcanism in Germany (In the Eifel district of the Rhine valley) only ceased 10,000 years ago, there are almost certainly high-enthalpy resources yet to be developed there, as regions with volcanism within the last million years often remain highly prospective for high-enthalpy reservoirs [35]. Nevertheless, the exploitation of high enthalpy resources is still effectively confined to countries with conspicuous active volcanism, such as Italy [43] and the countries of the circum-pacific "Ring of Fire," not least Japan [30]. The management of geothermal reservoirs requires judicious design and operation of both production and reinjection boreholes - the latter being used not only to prevent the environmental damage which discharge of hot and (usually) briny spent geothermal fluids to surface waters would cause, but also to maintain reservoir pressures at depth. In doing so, a delicate compromise must be negotiated between injecting so close to the production zones that the temperature of the produced fluids is reduced and injecting so far away that the desired pressure maintenance effects are not achieved. This balancing act is made no simpler by the tendency for thermal contraction fracturing to increase the permeability where cooler reinjectates enter the high-temperature reservoir [44]; a zone that seemed suitably remote from the production zones can become more intimately hydraulically connected with it over time, as these thermal contraction fractures propagate. A further consideration is the minimization of undesirably large seismic events. Thus the management of a geothermal reservoir is always a work in progress, with the tasks of production and reinjection being assigned to different wells over time. Additional "make-up" wells are typically required to maintain total production rates as the exploitation of a reservoir matures [45].

As further wells become available, their geological and production characteristics gradually expand the knowledge base for the reservoir, allowing refinement — or even wholesale replacement — of the prevailing conceptual model that is used to inform reservoir management decisions [43]. Furthermore, as the database of seismic events (natural and induced) in and around the reservoir grows, the identification of important geological structures and features (such as the zone of brittle/plastic transition) becomes clearer [30,43]. Indeed, as shown by Ryan and Shalev [31], correlations between seismic velocity and in situ temperatures could even make remote sensing of reservoir temperatures feasible. Thus an overall geothermal reservoir model comprises an assemblage of mutually consistent geological [43], geophysical [30,31] and hydrogeological models [43] should be developed in parallel, and iteratively updated to achieve harmonious coupling between them. The overall aim is a robust and constantly-evolving conceptual model of each geothermal reservoir, which is carefully adjusted to ensure that as much consistency as possible is achieved between concepts and available data. With this in place, rational management decisions are facilitated.

\subsection{Design, Operation and Maintenance of Energy Conversion Technologies}

The simplest geothermal direct-use systems require no more technology than conventional plumbing to deliver their benefits: this is the case, for instance, with low-enthalpy resources used for balneological purposes, or mid-enthalpy resources used for space heating. Depending on the composition of the 
geothermal fluid (whatever its enthalpy), heat-exchangers may be required even for these purposes, and these can be costly where fluid compositions would tend to give rise to either corrosion or clogging with mineral scales or biofilms.

It is at the extremes of enthalpy that technological requirements become most exacting for those very low enthalpy resources (Figure 1) that can only be usefully exploited using heat-pumps, robust approaches to design, installation, operation and maintenance of the pumps is essential. The introduction of legal requirements for a certain proportion of on-site renewable energy production for all new commercial buildings of a certain size led to a boom in demand for GCHPS in the UK [15]. However, the policing of this rule was weak, with the result that tokenism crept into too many designs: too many builders were content simply to obtain approval to proceed with their development, and did not care if the supposed $10 \%$ renewable technology actually worked in the long-run. This led to installation of many under-sized GCHPS, as became apparent some years later when a publicly-funded national study of system performance revealed actual COPs averaging only 2.2-significantly lower than the typical design values $(>3)$. Detailed modelling of typical installations revealed that the government-approved standard for GCHPS design actually leads to under-sizing of the subsurface heat-exchange arrays, thereby adding an additional $20 \%$ to the electricity demand for the heat-pumps [46]. This is but another example of a situation in which political will was not sufficiently under-pinned by a priori engineering rigor. It also underlines the importance of fully considering future operational conditions at the design stage.

For mid-enthalpy systems, direct use of geothermal resources for space heating typically does not require use of heat-pumps; heat exchangers and circulation pumps are all that is required to deliver heat to district pipe networks, albeit the inclusion of hot water storage tanks has recently been shown to decrease reliance on peak-up or back-up boiler plant [47]. Where the temperature of mid-enthalpy systems approaches or exceeds $100{ }^{\circ} \mathrm{C}$, it is also possible to convert at least part of the energy to electricity, by means of binary cycle power plants, in which a secondary working fluid with a far lower boiling point than water is converted into high-pressure vapour, which then spins a turbine in a closed-loop cycle. Although the secondary working fluid can be an ammonia/water mixture, as in the Kalina Cycle [48], the most widespread binary cycles use an organic compound (typically butane, pentane or a proprietary refrigerant), with the resultant systems being termed "Organic Rankine Cycle" (ORC) plants [19]. ORC technology has been increasingly used and refined since the 1980s and may now be regarded as a mature technology. As such, the design principles are now well established, and the frontiers of research currently focus on maximization of efficiency, extending the lower temperature threshold for ORC applications, and extending the applicability of the technology by reducing costs. Two examples of the latter may be cited:

(i) The development of small, modular ORC plants that can be rapidly deployed to remote areas as a pioneer power generation technology [19]. This raises the possibility of single wellhead ORC operations during geothermal field development, helping provide the power for drilling of further wells. (Hitherto, wellhead turbines have been restricted to atmospheric venting or back-pressure steam turbine units [6]).

(ii) Hybrid power plants, in which waste heat from other processes is harnessed together with mid-enthalpy geothermal energy in combined heat and power systems that are more efficient than would be the case were either heat source used in isolation [8]. 
Although there is no strict upper limit for ORC applications, on the grounds of capital cost the technology of choice for high enthalpy systems is, and is likely to remain, the steam turbine. Dry steam fields that can be used directly to supply turbines are globally rare [7]; far more common are flash systems, in which super-heated water is converted to high-pressure steam by pressure adjustment; the steam is separated and used in the turbine while the separated water is typically harnessed for direct use before being reunited with turbine exhaust condensate for reinjection. Single- or double-flash systems may be used, dependent on the enthalpy and desired yield of the system [6-8]. While steam turbines are a very mature technology, most applications to date have been in the fossil fuel sector, in which the purity of the steam delivered to the turbine is under the control of the plant operator. In contrast, the steam harnessed in geothermal systems is natural, and thus subject to variations in chemical composition - both between different systems and within any one systems, depending on reservoir dynamics. This means that the maintenance of geothermal flash power plant is subject to greater uncertainty and risk than tends to be the case in, say, a coal-fired power plant [49].

\subsection{Socio-Economic Constraints on Geothermal Energy Use}

Like any other energy resource, geothermal is subject to constraints arising from societal preferences and economic exigencies. These constraints are experienced across the full range of enthalpies and technologies. For instance, in the case of very low-enthalpy systems exploited using heat-pumps, while the levelised cost of heat may already be competitive with gas heating, the balance between capital expenditure (capex) and operating expenditure (opex) is quite different between the two: the marginal capex cost of replacing a gas boiler where the gas grid connection already exists is typically far less than the capex cost of installing a GCHPS from scratch. On the other hand, the opex costs of the GCHPS are likely to be far lower than those of the gas-fired system, because three-quarters of the heat delivered by a GCHPS is effectively sourced free of charge from the subsurface, whereas every Joule of heat delivered by a gas-fired system comes from purchased fuel. However, the scale of the capex cost can be a powerful disincentive to invest in GCHPS, despite lower total life-cycle costs. The disincentives are even more marked where the party paying for the capex (e.g., a house building firm) is different from the party who will benefit from the low opex (i.e., the house occupant). Such an impasse can only be overcome where mandatory rules favour the reduction in carbon emissions that a GCHPS offers in comparison to a gas-fired system [15]. Such mandates are common in Europe, but far less socially acceptable in North America, for instance.

A similarly high capex/opex ratio affects the production of electricity from mid-enthalpy resources: without a subsidy recognizing the value of the low carbon emissions of geothermal systems, electricity produced using ORC plants in Germany cannot compete with fossil-fuelled and nuclear power production [42]. Even though the economics of direct-use are generally far more favourable, there is still a challenge in displacing incumbent energy systems, due to the initial capex penalty of deep drilling and installing a district heating network. Again, technology "lock-in" is unlikely to be overcome by market forces alone, and governmental incentives are likely to be required if the full potential of mid-enthalpy geothermal resources is to be realized.

This in turn demands that public opinion be sufficiently in favour of geothermal energy. Public approval cannot be taken for granted. There is good evidence that provision of information helps 
improve the approval rating of geothermal, yet perceived risks (which bear little relation to reality, and are possibly driven by the negative publicity surrounding other subsurface technologies, such as shale gas) led to a majority of participants in an Australian survey favouring siting of geothermal wellfields far from communities [11]. This is at odds with the requirements for district heating (which is, admittedly, of little concern in the warm Australian climate, where interest in geothermal has focused far more on its potential to produce electricity). It is also odds with the complete public ease with extensive, long-established urban geothermal wellfields in Paris and Reykjavik, for instance.

The higher the enthalpy, the larger-scale must be the socio-economic framework within which geothermal energy is developed. Thus issues of energy security and balance of payments can favour the development of high-enthalpy geothermal resources. A case in point is Chile, which is the world's largest producer of copper, yet is heavily-dependent on imported fossil fuels for most of its energy needs. While hydropower has significant potential in the south of the country, in the far distant north where the copper mines are located the climate is arid to hyper-arid and hydropower potential is therefore negligible. However, the same volcanic processes that gave rise to the copper orebodies continue to give rise to significant deep hydrothermal circulation systems, several of which are highly prospective for geothermal power production. As much as $30 \%$ of the total power demand in the mining region could be met by development of geothermal resources identified to date [32], significantly reducing greenhouse gas emissions at the same time.

\section{Gaps Analysis of Geothermal Innovation: Towards a Whole-System Research Agenda}

For all the advantages it offers, geothermal remains one of the least-developed of the renewables [10]. This is despite the fact that high-enthalpy geothermal can already out-compete wind and solar on the basis of levelised costs of energy, as well as providing baseload service that are beyond the capability of those technologies. Geothermal district heating can already have a lower levelised cost than gas in many cases. However, uptake of geothermal continues to be hindered by its particularly high capex/opex ratio, which makes it an unconventional investment opportunity. One of the principal causes of this high ratio is the scale and uncertainty of resource characterization: where resource estimation for a wind farm will typically require only $1 \%$ of the total project cost, for geothermal it averages $47 \%$ [50]. There is therefore great value in any development that streamlines geothermal exploration activities [3,24,28-30,35,51].

Drilling and completion of wells is a large component of the geothermal capex burden, which has to date resisted many attempts at cost reduction. This is partly because geothermal drilling is but one small part of global drilling market that remains dominated by the hydrocarbon sector, in which the high market value of the commodity sought has tended to lessen pressures to reduce drilling costs. Furthermore, the high temperatures and pressures encountered in geothermal wells that intercept high-enthalpy reservoirs considerable exceed those encountered in hydrocarbon wells, so that very particular challenges arise in relation to mechanical processes and the performance of engineering materials [52]. For instance, drill-bits commonly used to achieve rapid rates of penetration in deep hydrocarbon wells (such as polycrystalline diamond compact bits rotated by rotor/stator devices actuated by drill mud, and conventional air- or water-actuated down-the-hole-hammer (DTTH) devices) will not function where high losses of drilling fluid occur to the strata (which is common in buried volcanic rock sequences containing lava tubes), nor where temperatures exceed the stability range of the 
elastomers used in the rotating or reciprocating components. Hence recent innovations have included the development of novel materials that will allow DTTH operations at pressures in excess of $250{ }^{\circ} \mathrm{C}$ [53]. Alternative cutting technologies that are insensitive to formation temperatures have also been developed such as plasma torches that ablate the rock at temperatures as high as $4500{ }^{\circ} \mathrm{C}[54,55]$ and a "ram accelerator" technology derived from gun technology, in which high velocity projectiles are fired at the bottom of the borehole at such a velocity that both the rock and the projectile vaporize [56]. Similarly, downhole deployment of lasers could offer a rapid and controllable technique for enhancing connectivity between wells and the pore networks in the surrounding reservoir rocks [57]. Such promising technologies have the potential to more than double rates of penetration, install casing during drilling and minimize the number of time-consuming and unproductive "trips" of the downhole assembly out of the hole; together, these measures could reduce geothermal drilling and completion costs by more than $50 \%$. However, significant technical challenges remain, including the challenge of ensuring borehole stability when the wall rocks exceed melting point [55], and the difficulties of obtaining good records of the geology encountered when there is no core or even chippings to examine. Incremental advances in more conventional reservoir stimulation approaches must also be pursued, such as "soft" thermal [44] and chemical stimulation of permeability.

At the other extreme of the enthalpy spectrum, there has been a tendency to achieve cheaper well completions for GCHPS by implementing lesser standards of casing and cementing than would be used in conventional water wells of similar depth. This tendency is particularly prevalent in the case of closed-loop GCHPS, but it should be stoutly resisted as it will often lead to undesirable (and even illegal) inter-connection of separate aquifers, to the detriment of water resources [21].

In the realm of geothermal reservoir development and management, there remains vast scope for advances in geophysical prospecting tools, both in refining existing tools for geothermal applications and in developing entirely new tools. Increasingly, it is combinations of tools with differing physical basis that is proving most useful in achieving less equivocal signatures of reservoir geometries and hydrogeothermal properties [23,30,31]. Hence advances in joint inversion of different types of geophysical data must remain a property in geothermal research. It is important to stress that the use of such multi-physics approaches to reservoir characterization should not be restricted to the exploration phase of geothermal development but can provide invaluable insights into the evolution of thermo-physical conditions within productive reservoirs [30].

In terms of geothermal energy conversion technologies, advances in plant design that allow efficient operation across a wider range of input temperatures and pressures would allow geothermal to extend its range of application from typical baseload applications to dispatchable service - something that few other renewable technologies can offer. At the simplest level, this might be achieved by smarter design and operation of storage facilities within direct-use systems; in electricity production, dynamic adjustment of working fluid properties could allow turbines to be operated closer to their optimal conditions over a wider range of input fluid conditions.

Finally, there is a continuing need for advances in the objective assessment and minimization of undesirable environmental side-effects of geothermal exploitation. To give but one example, there has as yet been very little examination of the "water-energy nexus" for the case of geothermal. Where geothermal is exploited in humid countries, with rain-fed agriculture and abundant water resources, the water-energy nexus may not yet be too pressing. However, in water-scarce countries with large and 
growing populations - such as most of eastern Africa and the "Cono Sur" of South America - a perfect storm is brewing [35]: ever-expanding demand for reliable renewable energy is prompting geothermal developments in regions where increasingly sparse ground water resources are the sole source of potable water supply. In many cases, there may be no direct hydraulic continuity between deep geothermal reservoirs and shallow groundwater recharge zones - in which case the renewability of the geothermal resource itself may be questionable. In some cases, however, hydraulic continuity will exist, albeit it may be masked by the very large spatial and temporal scales over which depletion of ground water resources might finally become apparent (reflecting the slow velocities of Darcian subsurface flow, the vast volumes of ground water stored in undeveloped aquifers, and the considerable distances between zones of aquifer recharge and natural discharge). It has long been appreciated [58] that the response of ground water systems to development depends on a case-specific interplay between (at least some) depletion of long-term storage, induced increases in recharge and/or decreases in natural discharge. Any robust appraisal of the geothermal water-energy nexus simply must address these hydrodynamics in a rigorous manner.

\section{Conclusions}

Recent advances in reservoir characterization techniques are beginning to narrow the bounds of exploration uncertainty, both by improving estimates of reservoir geometry and properties, and by providing pre-drilling estimates of temperature at depth. Advances in drilling technologies and management have potential to significantly lower initial capex, while operating expenditure is being further reduced by more effective reservoir management - supported by robust models — and increasingly efficient energy conversion systems (flash binary and heat exchange for direct-use). Advances in characterization and modelling are also improving management of shallow low-enthalpy resources that can only be exploited using heat-pump technology. Taken together with increased public appreciation of the benefits of geothermal, the technology is finally ready to take its place as a mainstream renewable technology, exploited far beyond its traditional confines in the world's volcanic regions.

\section{Acknowledgments}

This paper was prepared to provide an overview and summary of the papers published in a Special Issue of Energies on geothermal energy, which was guest-edited by the present author. The author gratefully acknowledges the original invitation from the editorial team of Energies to serve as Guest Editor, and for their excellent support throughout the process of publishing the Special Issue.

Besides placing the papers in the Special Issue in their broader context, this paper draws on the wider literature and the experiences of the author in the geothermal sector, both as a university researcher and as an adviser to industry. Most recently, this has been under the auspices of the Horizon 2020 project "LoCAL" (Low-Carbon After-Life for Coalmines: geothermal energy), funded by the European Commission under the auspices of the Research Fund for Coal and Steel (Contract No. RFCR-CT-2014-00001). However, the views expressed are solely those of the author, and cannot be construed as representing those of any of the private and public entities with which he has collaborated. 


\section{Conflicts of Interest}

The author declares no conflict of interest. Although he is a founding non-executive director of Hotspur Geothermal Group (formerly Cluff Geothermal Ltd.), none of the work reported here was funded by that company; nor do the findings of this paper give that company any competitive advantage.

\section{References}

1. Armstead, H.C.H. Geothermal Energy: Its Past, Present and Future Contributions to the Energy Needs of Man; Spon: London, UK, 1978.

2. Stober, I.; Bucher, K. History of geothermal energy use. In Geothermal Energy: From Theoretical Models to Exploration and Development; Stober, I., Bucher, K., Eds.; Springer-Verlag: Berlin/Heidelberg, Germany, 2013.

3. McCay, A.T.; Harley, T.L.; Younger, P.L.; Sanderson, D.C.W.; Cresswell, A.J. Gamma-ray spectrometry in geothermal exploration: State of the art techniques. Energies 2014, 7, 4757-4780.

4. Younger, P.L. Energy: All That Matters; Hodder and Stoughton/John Murray: London, UK, 2014.

5. Zhang, P.; Watanabe, K.; Eishi, T. Habitual hot-spring bathing by a group of Japanese macaques (Macaca fuscata) in their natural habitat. Am. J. Primatol. 2007, 69, 1425-1430.

6. Dickson, M.H.; Fanelli, M. Geothermal Energy: Utilization and Technology; Earthscan: London, UK, 2005.

7. DiPippo, R. Geothermal Power Plants: Principles, Applications, Case Studies and Environmental Impact, 3rd ed.; Butterworth-Heinemann: Oxford, UK, 2012.

8. Heberle, F.; Brüggemann, D. Thermoeconomic analysis of hybrid power plant concepts for geothermal combined heat and power generation. Energies 2014, 7, 4482-4497.

9. Garnish, J.; Brown, G. Geothermal energy. In Renewable Energy. Power for a Sustainable Future, 3rd ed.; Boyle, G., Ed.; Open University-Oxford University Press: Oxford, UK, 2012; pp. 409-459.

10. Rybach, L. Geothermal power growth 1995-2013-A comparison with other renewables. Energies 2014, 7, 4802-4812.

11. Carr-Cornish, S.; Romanach, L. Differences in public perceptions of geothermal energy technology in Australia. Energies 2014, 7, 1555-1575.

12. Geothermal Risk Mitigation Facility for Eastern Africa. Available online: http://www.grmf-eastafrica.org (accessed on 20 March 2015).

13. Glassley, W.E. Geothermal Energy: Renewable Energy and the Environment, 2nd ed.; CRC Press: Boca Raton, FL, USA; Taylor \& Francis: London, UK, 2015.

14. Younger, P.L. Hydrogeological challenges in a low-carbon economy. Q. J. Eng. Geol. Hydrogeol. 2014, 47, 7-27.

15. Rees, S.; Curtis, R. National deployment of domestic geothermal heat pump technology: Observations on the UK experience 1995-2013. Energies 2014, 7, 5460-5499.

16. Björnsson, S. (Ed.) Geothermal Development and Research in Iceland; Orkustofnun: Reykjavik, Iceland, 2010; p. 40. Available online: http://www.nea.is/media/utgafa/GD_loka.pdf (accessed on 29 September 2015). 
17. Gambardella, B.; Cardellini, C.; Chiodini, G.; Frondini, F.; Marini, L.; Ottonello, G.; Vetuschi Zuccolini, M. Fluxes of deep $\mathrm{CO}_{2}$ in the volcanic areas of central-southern Italy. J. Volcanol. Geotherm. Res. 2004, 136, 31-52.

18. Holm, A.; Jennejohn, D.; Blodgett, L. Geothermal Energy and Greenhouse gas Emissions; Geothermal Energy Association: Washington, DC, USA, 2012. Available online: http://geo-energy.org/ reports/GeothermalGreenhouseEmissionsNov2012GEA_web.pdf (accessed on 29 September 2015).

19. Nusiaputra, Y.; Wiemer, H.; Kuhn, D. Thermal-economic modularization of small, Organic Rankine Cycle power plants for mid-enthalpy geothermal fields. Energies 2014, 7, 4221-4240.

20. Friðleifsson, G.Ó.; Elders, W.A.; Albertsson, A. The concept of the Iceland deep drilling project. Geothermics 2014, 49, 2-8.

21. Younger, P.L. Ground-coupled heating-cooling systems in urban areas: How sustainable are they? Bull. Sci. Technol. Soc. 2008, 28, 174-182.

22. Banks, D. Thermogeology: Ground-Source Heating and Cooling, 2nd ed.; Wiley Blackwell: Chichester, UK, 2012; p. 526.

23. Hermans, T.; Nguyen, F.; Robert, T.; Revil, A. Geophysical methods for monitoring temperature changes in shallow low enthalpy geothermal systems. Energies 2014, 7, 5083-5118.

24. Rodríguez Díez, R.; Díaz-Aguado, M.B. Estimating limits for the geothermal energy potential of abandoned underground coalmines: A simple methodology. Energies 2014, 7, 4241-4260.

25. Adams, R.; Younger, P.L. A strategy for modeling ground water rebound in abandoned deep mine systems. Ground Water 2001, 39, 249-261.

26. Law, R. Deep Geothermal Heat Production-Single Well Trial; Ground-Source Heat Pump Association: Uxbridge, UK, 2014. Available online: http://www.gshp.org.uk/DeMontfort/Geothermal EngineeringLtd.pdf (accessed on 20 August 2015).

27. Younger, P.L.; Manning, D.A.C. Hyper-permeable granite: Lessons from test-pumping in the Eastgate Geothermal Borehole, Weardale, UK. Q. J. Eng. Geol. Hydrogeol. 2010, 43, 5-10.

28. Westaway, R.; Younger, P.L. Accounting for palaeoclimate and topography: A rigorous approach to correction of the British geothermal dataset. Geothermics 2013, 48, 31-51.

29. Weides, S.; Majorowicz, J. Implications of spatial variability in heat flow for geothermal resource evaluation in large foreland basins: The case of the Western Canada Sedimentary Basin. Energies 2014, 7, 2573-2594.

30. Suzuki, Y.; Ioka, S.; Muraoka, H. Determining the maximum depth of hydrothermal circulation using geothermal mapping and seismicity to delineate the depth to brittle-plastic transition in northern Honshu, Japan. Energies 2014, 7, 3503-3511.

31. Ryan, G.; Shalev, E. Seismic velocity/temperature correlations and a possible new geothermometer: Insights from exploration of a high-temperature geothermal system on Montserrat, West Indies. Energies 2014, 7, 6689-6720.

32. Procesi, M. Geothermal potential evaluation for northern Chile and suggestions for new energy plans. Energies 2014, 7, 5444-5459.

33. Italiano, F.; de Santis, A.; Favali, P.; Rainone, M.; Rusi, S.; Signanini, P. The Marsili Volcanic Seamount (southern Tyrrhenian Sea): A potential offshore geothermal resource. Energies 2014, 7 , 4068-4086. 
34. Elders, W.A. The potential for on- and off-shore high-enthalpy geothermal systems in the USA. In Proceedings of the 40th Workshop on Geothermal Reservoir Engineering, Stanford University, Stanford, CA, USA, 26-28 January 2015.

35. Younger, P.L. Missing a trick in geothermal exploration. Nat. Geosci. 2014, 7, 479-480.

36. Scott, S.; Driesner, T.; Weis, P. Geologic controls on supercritical geothermal resources above magmatic intrusions. Nat. Commun. 2015, 6, doi:10.1038/ncomms8837.

37. Ferguson, G.; Woodbury, D. Observed thermal pollution and post development simulations of low-temperature geothermal systems in Winnipeg, Canada. Hydrogeol. J. 2006, 17, 1206-1215.

38. Fry, V.A. Lessons from London: regulation of open-loop ground source heat pumps in central London. Q. J. Eng. Geol. Hydrogeol. 2009, 42, 325-334.

39. Birks, D.; Younger, P.L.; Tavendale, L.; Coutts, C.; Parkin, G.; Button, P.; Whittall, S. Groundwater reinjection and heat dissipation: Lessons from the operation of a large groundwater cooling system in Central London. Q. J. Eng. Geol. Hydrogeol. 2015, 48, 94-103.

40. Gandy, C.J.; Clarke, L.; Banks, D.; Younger, P.L. Predictive modelling of groundwater abstraction and artificial recharge of cooling water. Q. J. Eng. Geol. Hydrogeol. 2010, 43, 279-288.

41. Neuberger, P.; Adamovský, R.; Šed'ová, M. Temperatures and heat flows in a soil enclosing a slinky horizontal heat exchanger. Energies 2014, 7, 972-987.

42. Agemar, T.; Weber, J.; Schulz, R. Deep geothermal energy production in Germany. Energies 2014, 7, 4397-4416.

43. Fulignati, P.; Marianelli, P.; Sbrana, A.; Ciani, V. 3D geothermal modelling of the Mount Amiata hydrothermal system in Italy. Energies 2014, 7, 7434-7453.

44. Gholizadeh Doonechaly, N.; Abdel Azim, R.R.; Rahman, S.S. A study of permeability changes due to cold fluid circulation in fractured geothermal reservoirs. Groundwater 2015, doi:10.1111/gwat.12365.

45. Sanyal, S.S.; Morrow, J.W. An investigation of drilling success in geothermal exploration, development and operation. Geotherm. Resour. Counc. Trans. 2011, 35, 233-237.

46. Underwood, C. On the design and response of domestic ground-source heat pumps in the UK. Energies 2014, 7, 4532-4553.

47. Kyriakis, S.A. Effect of heat storage in geothermal district heating. In Proceedings of the ASME-ATI-UIT 2015 Conference on Thermal Energy Systems: Production, Storage, Utilization and the Environment, Naples, Italy, 17-20 May 2015.

48. Kalina, A.I.; Leibowitz, H.M. Application of the Kalina Cycle technology to geothermal power generation. Geotherm. Resour. Counc. Trans. 1989, 13, 605-611.

49. Atlason, R.; Oddsson, G.; Unnthorsson, R. Geothermal power plant maintenance: Evaluating maintenance system needs using quantitative Kano Analysis. Energies 2014, 7, 4169-4184.

50. Harber, A. Study into the Potential for Deep Geothermal Energy in Scotland; Scottish Government Project Number: AEC/001/11; AECOM/Scottish Government: Edinburgh, UK, 2013; Volume 1, p. 216. Available online: http://www.gov.scot/Publications/2013/11/2800/9 (accessed on 29 September 2015).

51. Younger, P.L.; Feliks, M.E.J.; Westaway, R.; McCay, A.; Harley, T.L.; Elliott, T.; Stove, G.D.C.; Ellis, J.; Watson, S.; Waring, A. Renewing the exploration approach for mid-enthalpy systems: Examples from northern England and Scotland. In Proceedings of the World Geothermal Congress 2015, Melbourne, Australia, 19-25 April 2015; p. 7. 
52. Finger, J.; Blankenship, D. Handbook of Best Practices for Geothermal Drilling; Report SAND2010-6048; Sandia National Laboratory: Albuquerque, NM, USA, 2010; p. 84. Available online: http://wwwl.eere.energy.gov/geothermal/pdfs/drillinghandbook.pdf (accessed on 1 October 2015).

53. United States Department of Energy. Percussive Hammer Enables Geothermal Drilling. Available online: http://energy.gov/eere/success-stories/articles/percussive-hammer-enables-geothermal-drilling (accessed on 1 October 2015).

54. Kristofič, T. PLASMABIT ${ }^{\text {TM }}$ technology presentation. In Proceedings of the 2012 Geothermal District Heating (GeoDH) Project Conference: Brussels, Belgium, 9 October 2012; p. 11. Available online: http://geodh.eu/wp-content/uploads/2012/10/PlasmaBit-Kristofic.pdf (accessed on 1 October 2015).

55. Bazargan, M.; Gudmundsson, A.; Meredith, P.; Forbes, N.; Soliman, M.; Habibpour, M.; Rezaee, A. Wellbore instability during plasma torch drilling in geothermal reservoirs. In Proceedings of the 49th US Rock Mechanics/Geomechanics Symposium, American Rock Mechanics Association, San Francisco, CA, USA, 28 June-1 July 2015.

56. Russell, M.C. Ram Accelerator System; Patent No. WO2014149173 A1/US20140260930, 25 September 2014. Available online: http://www.google.com/patents/WO2014149173A1 (accessed on 1 October 2015).

57. United States Department of Energy, High power laser innovation sparks geothermal power potential. Available online: http://energy.gov/eere/geothermal/articles/high-power-laser-innovationsparks-geothermal-power-potential (accessed on 1 October 2015).

58. Theis, C.V. The source of water derived from wells: Essential factors controlling the response of an aquifer to development. Civil Eng. 1940, 10, 277-280.

(C) 2015 by the authors; licensee MDPI, Basel, Switzerland. This article is an open access article distributed under the terms and conditions of the Creative Commons Attribution license (http://creativecommons.org/licenses/by/4.0/). 